American Journal of Infectious Diseases 4 (2): 92-95, 2008

ISSN 1553-6203

(C) 2008 Science Publications

\title{
Evaluation Of Growth Indices In Children With Recurrent Pharyngotonsilitis Due To Adenotonsilar Hypertrophy: A Case Control Study
}

\author{
Keramat Mozafarinia \\ Department of Ear, Nose, Throat, Head and Neck surgery, \\ Kerman medical sciences university, Kerman, Iran
}

\begin{abstract}
Children in 2 to 9 years old is sensitive to growth. Chronic infectious diseases may affect on child growth and recurrent pharyngotonsilitis due to adenotonsilar hypertrophy is main disease in children and may cause failure to thrive (FTT). The aim pf this study was to investigate relation between growth rate and adenotonsillar hypertrophy in Iranian subample children. We selected 76 children between 2-9 years old who suffered from chronic adenotonsilar hypertrophy and tonsillitis more than two years evaluated and compared with normal control group, by the results of the development indices. Analysis was done by EPI-6 and SPSS-12 soft wares. According to revealed results in both groups all of percentile less than 3 rd were WAP $=23.8, \mathrm{WHP}=17.8, \mathrm{HAP}=18.1$ $(\mathrm{P}=0.006)$ and WAP was significant difference between two groups $(\mathrm{P}=0.045)$. Also there is no significant difference for WHP, WHZ, HAZ. Chronic and recurrent infection of adenotonsilar hypertrophy affecting body growth process and diminishes weight/age and height/age ratio and percentile.
\end{abstract}

Key words: Adenotonsilar hypertrophy, growth, child, FTT

\section{INTRODUCTION}

Growth procedure in children is a very important issue and has a close relationship with children's health. Due to this, health systems around the worlds allocate a huge cost to supervise and control the growth procedure in children and they try to find the factors that interrupt this procedure and try to eliminate them as soon as possible. Among the many factors which make interruption in growth procedure, chronic infections in childhood is very important and reported repeatedly. Pharyngitis and chronic bacterial adenotonsilitis are the ones with high prevalence among childhood infections ${ }^{[1,2]}$.

On the other hand, repeated and chronic adenotonsilar infections cause an irreversible hypertrophy and problems in ingestion and some degree of obstruction in upper respiratory system. It's possible that the above mentioned matters and the other problems such as shortage in growth hormone secretion, loss of appetite, dysphagia and cause an interruption in growth procedure, so this research is based on comparison of wheight and height between the children in case and control groups. Due to the reports from Brodsky and coworkers chronic adenotonsilar hypertrophy cause an overload of pathogen bacteria specially b-lactamase enzyme secreting species in tonsils and adenoid tissues ${ }^{[1,2,3,4]}$.
Obstruction of upper respiratory airway due to adenotonsilar hypertrophy in severe and progressive cases cause corpulmonale, nocturnal hypertension of pulmonary arteries, alveolar hypoventilation and even heart failure ${ }^{[5,6,7,8,9,10]}$.

Fortunately all of complications are reversible after adenotonsilectomy ${ }^{[8,11]}$. Chronic adenotonsilar hypertrophy is the most prevalent cause of sleep apnea; nocturnal growling in children is the significant symptom in sleep apnea. Today it's proved that chronic adenotonsilar hypertrophy and subsequently obstruction of upper respiratory airway cause an interruption in normal growth procedure by severely reducing the secretion of growth hormone in REM phase of sleeping ${ }^{[16,17,18,19,20]}$.

Finally there is some reports that obstruction of upper respiratory airway due to chronic adenotonsilar hypertrophy cause an increased calories consumption by increasing respiratory work and cause and loss of weight $^{[21]}$.

In addition loss of weight maybe is a result of reduced growth hormone secretion, loss of appetite and dysphagia (low calories intake), nocturnal hypoxia and nocturnal acidosis ${ }^{[22,23]}$, which by the $\mathrm{T}$ and $\mathrm{A}$ operation, weight and height of the child is in normal range. 
Problems and restriction which should be considered are:

- Cases and control groups should be from one family so the genetic ,hereditary , senile and nutritional specifications are the same.

Sisters or brothers in control groups shouldn't have adenotonsilar hypertrophy.

- Cases and control groups shouldn't have any other chronic disease which may make an interruption in growth procedure.

- Measurements must be precise so measurement of weight was made by an precise scale with precision rate of $0.1 \mathrm{Kg}$, age from identity card and, height measured in $\mathrm{cm}$.

So with considering and preparing the above mentioned problem in front of this research was solved.

\section{MATERIALS AND METHODS}

A case-control study was designed for compare growth percentiles and indexes between children with adenotonsilar hypertrophy and repeated adenotonsilitis who were elected for the surgery and normal individuals. On the basis of prevalence of failure to thrive (FTT) 20\%, sample size was estimated 80 persons in each group.

Cases were selected through children 2-9 years old with adenotonsilar hypertrophy and repeated adenotonsilitis who were choose for adenoidectomy. The nearest brother or sister of cases among 2-9 years ones was chosen to have the closest genetic and nutritional specifications as control group. The cases who didn't have brother or sisters with that consideration or who have them with adenotonsilar hypertrophy were eliminated from the study.

After ear nose throat exact physical examination of all samples, measurement of height and weight was done. Height in $\mathrm{cm}$, weight based on $\mathrm{Kg}$ with precision ratio of $0.1 \mathrm{Kg}$, age from identity card based on months. The members who had more than 4 standard deviations were eliminated from the study. By EPI-6 version software; Z scores and percentiles for the weight/age ratio (WAP), height/age (HAP) and weight/height (WHP) calculated for everyone. Then data analysis was done by SPSS-12 software. T teat and ANOVA test were used to compare above ratios between case and control groups. $\mathrm{p}<0.05$ was significant level in all tests. Research ethical rights were observed during this research.

\section{RESULTS AND DISCUSSION}

In this study 76 children were candidate of operation because of adenotonsilar hypertrophy with 76 sisters or brothers who have been in 2-9 years age group were analyzed and these findings was assessed.

In case group there were 27 girls and 49 boys and in control group there were 36 girls and 40 boys. The mean age for case group was 76.6 \pm 23 months (mean $\pm \mathrm{SD}$ ), and in control group it was $71.5 \pm 11$ $(\mathrm{P}>0.05)$. To determine growth interruption ratio and effect of adenotonsilar hypertrophy on growth procedure, growth indices of these children calculated and compared in case and control groups. The results of comparison between indices were in Table 1 . According to this table, WAP and HAP was significant $(\mathrm{p}=0.024, \mathrm{p}=0.006)$.

But there is no significant difference in WHP index. This showed that in FTT, weight and height both suffers and if the interfering factor eliminates both will improve. In Fig. 1 fewer than third percentiles are comprised for WAP, HAP, WHP indices. As seen in the WAP index there is a significant difference $(\mathrm{p}=0.004)$. According to WHP and HAP indexes despite the more cases were below third percentiles in the case group. There was no significant difference.

Table 1: Growth indices comparison in case and control group.

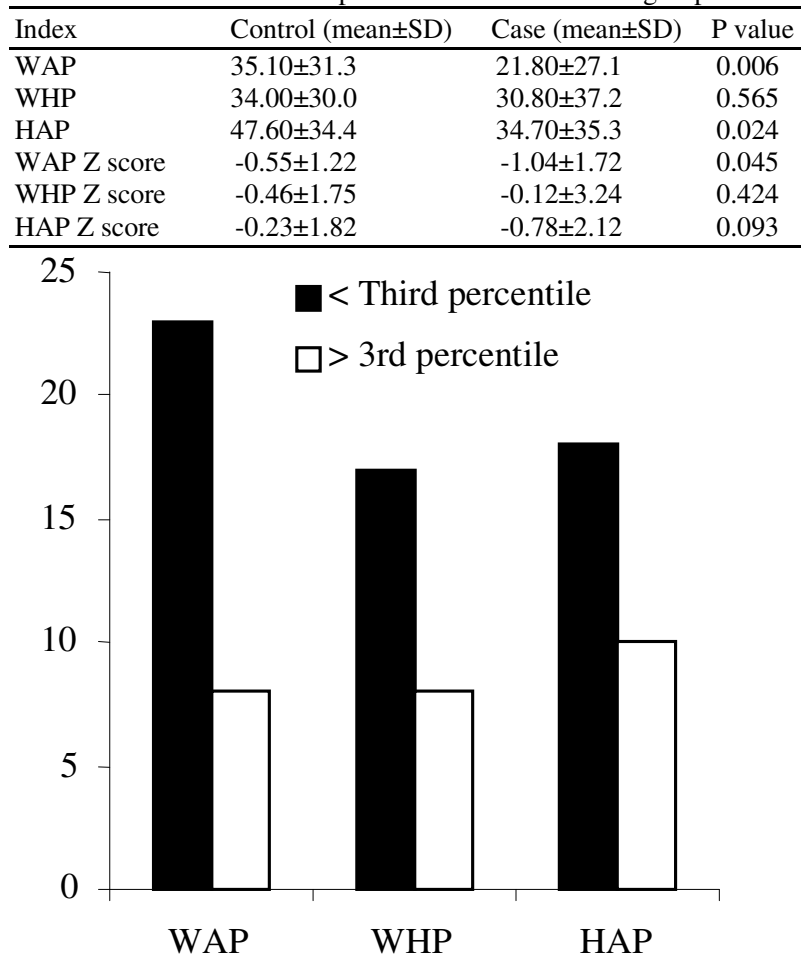

Fig. 1: Comparison of under 3rd percentile in sample 
Settling the growth indices of a child in normal range according to $\mathrm{WHO}$ definitions and conforming to normal growth percentiles are indicators of a healthy child.

So for assessment of children health around the world, it needed to obtain an assessment on the growth rate of children from the birth until the first decade of their life.

Methods for assessment of health and growth conditions among children are based on growth percentile and $\mathrm{Z}$ score. In this study, assessment of 76 children was based on growth percentile and $\mathrm{Z}$ score, too.

$\mathrm{Z}$ score is a method used in health houses for each child who admits in rural health houses or urban health centers. There is a form with a growth chart. This chart has 3 curves. The first curve percentile 3 , second curve percentile 10 and the third one percentile 97. Weight and height are measured and will be drawn based on child age.

This procedure will be repeated many times when the child is admitted and in this way by connecting the dots they will apply the growth curve. The growth rate of children is determined and analyzed through how the growth curve of every child is placed in order to these curves or is the curve uprising or downward.

If for any reason like infections inappropriate nutrition and chronic disease the growth is interrupted the first index which suffers is the weight it means that the weight for age ratio is decreased and if the interruption lasts a long time the height also will suffer .finally it means that the height for age will be decreased. As seen in this study the growth indexes in the children who suffers from chronic adenotonsilar hypertrophy is decreased.

So according to introduction chronic adenotonsilar hypertrophy could interrupt in normal growth procedure in many ways, also it can prepare a good condition for growth of pathogen bacteria specially B-lactamase enzyme producing species in adenotonsilar tissues ${ }^{[16,17]}$.

Nowadays its proved that obstructive apnea during sleeping that caused by adenotonsilar hypertrophy causes reduction in growth hormone IGF-1 (insulin growth factor $)^{[24]}$.

IGF-1 is a growth factor that has endocrine an paracrine effects and its secretion depends on growth hormone .most of IGF-1 in blood circulation is banded with a carrier protein named insulin growth factor binding protein-3 (IGF BP3). IGFBP3 synthesis is also controlled by secretion of growth hormone anatomical effects of growth hormone in body tissues are due to IGF-1 so serum levels of IGF-1 and IGFBP3 are considered for evaluation of growth hormone levels ${ }^{[25]}$ and after the adenotonsilar surgical operation increase in IGF-1 serum levels ${ }^{[9,22]}$ and increase in height and weight are significant.

In these assessments on 61 children who had surgical operation of adenotonsilectomy and comparison between them and 31 healthy children it was obvious that eliminating problems such as sleep apnea, nocturnal hypoxia and sleep interruption (agitation, efforts, changing body position) by adenotonsilectomy surgical operation will increase the growth rate in all of children, significantly.

In evaluation of growth procedure and its chemical markers ${ }^{[15,26]}$. In the children who had obstructive sleep apnea 70 children were in case group and 35 persons in control group were under study and analyzed.

This assessment showed that in the gap phase after the operation the weight for height and secretion of IGF-1, IGFBP3 are increased ${ }^{[22]}$.

In the study applied in a child international hospital in Dublin, Ireland ${ }^{27]}$. There was an evaluation between tonsillitis and abnormalities in weight and they measured the weight of 55 children before and after adenotonsilectomy surgical operation, the mean weight before operation was $9.85 \%$ more than mean standard normal weight for age .mean weight after operation was $22 \%$ more than mean standard normal weight for age.

In another report from royal Parkwill Victoria children hospital in Australia, it was an significant increase in weight after adenotonsilectomy surgical operation among $87 \%$ of children with FTT .but the growth rate in the children without FTT was not significant after operation .in another evaluation of weight and height percentile among 65 children before and after adenotonsilectomy operation in $25 \%$ of them (38 persons) weight percentile and in $12 \%$ ( 8 persons) height percentile was increased ${ }^{[29]}$.

In the other studies there was considered a significant role for chronic adenotonsilar hypertrophy in obstructive apnea and also increased calories consumption, loss of energy and FTT was reported $^{[21,30,31]}$.

In our study without consideration of causes and pathophysiology of adenotonsilar hypertrophy on growth procedure (decrease in growth hormone secretion .increase in calories consumption, loss of energy and low calories intake) it focused on comparison between growth rate in children with chronic adenotonsilar hypertrophy and healthy children in the same age group (same family) and to reach this goal they used three important indexes of growth; weight, height and age in case group the weight/age ratio with standard deviation of $21.8 \pm 27.1$ despite the control group that the standard deviation was 35.1 \pm 31.3 . $\mathrm{P}=0.006$ is significant and important. The ratio of height for age in case group $34.7 \pm 35.3$ and this standard deviation for control group was 47.6 \pm 34.4 $(\mathrm{p}=0.024)$. Also is significant and important .but in weight for height ratio $\mathrm{p}=0.565$ is significant and important as seen the results of our study are the same with most of the other studies in this field.

In table 1 all of the ratios mentioned above and standard deviations of growth indexes in case and control groups are brought totally.

Regarding to the results of this study and considering the previous studies which were discussed completely in different sections it shows that chronic adenotonsilar hypertrophy in children has an important effect on normal way of growth procedure and cause it to interruption. 


\section{REFERENCES}

1. Brodsky, L. and R.J. Koch, 1993. Bacteriology and immunology of normal and diseased adenoids in children. Arch. Otolaryngol. Head. Neck. Surg; 119: 821-27.

2. Brodsky, L. and J.F. Stanievich, 1987. A comparison of tonsillar size and oropharyngeal dimensions in children with obstructive adenotonsillar hypertrophy. Int. J. Pediatr. Otorhinolaryngol.; 13: 149-154.

3. Brodsky, L., L. Moore and J.F. Stanievich, 1988. The role of Haemophilus influenza in the pathogenesis of tonsillar hypertrophy in children. Laryngoscope; 98: 1055-62.

4. Brodsky, L., K. Radomski and J. Gendler, 1993. The effect of post operative in structions on recovery after tonsillectomy and adenoidectomy. Int. J. Pediatr. Otorhinolaryngol.; 25: 133-39.

5. Strandiny, J.R., G. Thomas, A.R. Wanley, P. Williams and A. Freeland, 1990. Effect of adenotonsillectomy on nocturnal hypoxemia, sleep disturbance. Lancet; 335: 249-53.

6. Perkin, R.M. and N.G. Anas, 1984. Pulmonary hypertension in pediatric patients. J. Pediatr; 105: 511-17.

7. Mullens, P.D., H.A. Nagaraj and G.T. Memurray, 1987. Upper airway obstruction resulting in corpulmonale. J. Ky. Med. Assoc.; 76: 233-39.

8. Menasbe, V.D., C. Ferrehi and M.S. Miller, 1965. Hyperventilation and corpulmonale due to chronic upper airway obstruction. J Pediatr.; 67: 198-204.

9. Machenzie, M. 1980. The pharynx. In Anonymous: Disease of the pharynx. New York. William Wood Co.

10. Brown, O.E., S.C. Manning and B. Ridenour, 1988. Corpulmonale secondary to tonsillar and adenoid hypertrophy: management consideration. Int. J. Pediatr. Otorhinolaryngol.;6:130-36.

11. Noonan, J.A. 1965. Reversible cor pulmonale due to hypertrophied tonsils and adenoid: studies in two cases. Circulation; 32: 164-69.

12. Zucconi, M. 1993. Habitual snoring and obstructive sleep apnea syndrome in children: effects of early tonsil surgery. Int. J. Pediatr. Otorhinolaryngol.; 26: 235-40.

13. Richardson, M.A. 1980. Evaluation of tonsils and adenoids in sleep apnea syndrome.; Laryngoscope,. 90: 1106-10.

14. Leach, J., 1992. Polysomnographic and clinical findings in children with obstructive sleep apnea. Arch. Otolaryngol. Head. Neck. Surg.; 118: 741-49.

15. Gibb, A.G., 1969. Unusual compications of tonsil and adenoid removal. Laryngol.; 83: 1159-64.

16. Williams, E.F., P. Woo, R. Miller and R.M. Kellman, 1991. The effect of adenotonsillectomy on growth in young children. Otolaryngol. Head. Neck. Surg.; 104: 509-16.

17. Schiffmann, R.J. Faber and A.I. Eidelman, 1985. Obstructive hypertrophic adenoids anf tonsils as a cause of infantile failure to thrive: reserved by tonsillectomy and adenoidectomy. Int. J. Pediatr. Otorhinolaryngol.; 9: 183-92.
18. Hodges, S., T. Ashikawa, I. Moriwaki et al., 1987. Tonsilar enlargement and failure to thrive. B.M.J.; 295: 541-42.

19. Chilba, S., T. Ashikawa, I. Miriwaki and et al., 1998. The influence of sleep breathing disorder on growth hormone secretion in children with tonsil hypertrophy. Nippon. Jibinkoka Kaiho,; 101: 87378. (Abstract).

20. Brouillette, R.T., S.K. Frenbach and C.E. Hunt, 1982. Obstructive sleep apnea in infants and children. J. Pediatr.; 100: 31-34.

21. Bland, R.M., S. Bulgare, J.C. Ventham et al., 2001. Total energy expenditure on children with obstructive sleep apnea syndrome. Eur. Respir. J.; 18: 164-9.

22. Bar, A., A. Tarask, Y. Sogev et al., 1999. The effect of adenotonsilectomy on serum insulin-like growth factor-I and growth in children with obstructive sleep apnea syndrome. J. Pediatr.; 135: 76-80.

23. Ahlqvistt-Rastad, J., E. Hultcrantz and II Svanholm, 1991. Children with tonsillar obstruction. Indicstion for efficacy of tonsillectomy. Acta. Pediatr. Scan.; 77: 831-35.

24. Ahlqvistt-Rastad, J., E. Hultcrantz, E. Melander and II Svanholm, 1992. Body growth in children with tonsillar enlargement and tonsillectomy. Int. J. Pediatr. Otorhinolaryngol.; 24: 55-61.

25. Van den Brande, J.L., 1992. Structure of human insulin like growth factors: relationship to function. In Sehofield, P.N. The insulin-like growth factors. 3rd ed. New York: Oxford medical publication; pp: 12-37.

26. Neimenen, P., T. Lopponen, U. Tolonen et al., 2000. Growth and biochemical markers of growth in children with snoring and obstructive sleep apnea. Pediatrics; 109: 655-61.

27. Conlon, B.J., M.J. Donnelly and D.P Meshane, 1997. Tonsilitis, tonsillectomy and weight disturbance. J. Pediatr. Otorhinolaryngol.; 42: $17-23$.

28. Freezer, N.J., I.K. Bucens and C.F. Robertson, 1995. Obstructive sleep apnea presenting as failure to thrive in infancy. J. Pediatr.; 31: 171-75.

29. Nuyons, M.R., S. Vedu, C. Basseti et al., 1999. Objective value of adenotonsilectomy in child. A prospective study of incidence of tonsillitis, snoring development before and after tonsillectomy. Int. J. Pediatr. Otorhinolaryngol.; 88: 893-9.

30. Herman, R. and B. Panjandeh, 1971. The effect of adenotoncillectomy on physical development of children.; 19: 241-45.

31. Ghehi, D., 2000. Sleep apnea in children.; 57:463-9. 